\title{
"AN OCULIST IN SWITZERLAND"
}

\author{
BY \\ JOHN FOSTER \\ LEEDS
}

THE account which follows is a précis of lectures given on this subject at the Royal Society of Medicine and the Tennent Institute. It describes the Swiss portion of an ophthalmic tour in August and September, 1946. The kindness of the heads of the various clinics during the visit, and in responding to numerous enquiries subsequently, is a matter for which I would like to express my gratitude.

The writer doubts if it is possible to see so much of ophthalmic interest in so small an area in any other part of the world. Switzerland is not only a creative amalgam of three European civilisations, but is also endowed with a most excellent transport system, has had 122 years of continuous peace, and has a firstclass precision engineering and pharmaceutical industry in addition.

\section{Basel}

Professor Brückner, the head of the University clinic, is the Doyen of Swiss Ophthalmology, and retires on reaching the age limit in 1947. Born the son of a Russian Professor of Geography in Zoppot, he received part of his training in Berlin, partly as assistant to Hering at Leipzig, and later held the Chair at Jena. He came from this last city to the Chair at Basel, with an interest in physiological optics, and a wonderful collection of apparatus. He delighted his new assistants on arrival, by doing the first Krönlein operation ever seen in Basel (with a chisel), and still takes a poor view of what he calls " anterior chamber surgeons." Apart from a stāndard textbook, his chief publications have been. on physiological optics (especially on dioptrics and colour vision), though there are many on clinical subjects.

His clinic of 74 beds is sixty years old; an excellent building by our standards, but considered out of date in Switzerland. His friend, the late Professor Bielschowsky, he says, described it as "like a sanatorium"-I suppose because there are many small high-ceilinged rooms.

The plans of the new clinic (of approximately the same beddage), will be available after the Basel Parliament has seen them in 1947 .

On going through the clinic the orderliness is most strikinga room for foreign reprints, a library, a room for the Professor's 
reprints, four chemical laboratories, and two for physiological optics.

I spent an hour with Fräulein Giger, who, runs the orthoptic department. She is a social worker who does this voluntarily in her spare time, including the necessary reading. She has a good grasp of the problem of " false projection," which is minimised by some continental schools in spite of Bielschowsky's teaching.

The professor, she says, is encouraging, but some of the younger men are not so interested. Although she has a Hamblin amblyoscope, more English apparatus would help. Most of her time is spent in treating amblyopia. The children put rings round dots of light on a board, and are admitted as in-patients for occlusion.

I also spent a similar period with the head biochemist. A good deal of research has been carried out here on the intra-ocular distribution of cholinesterase, so that they are particularly interested in the fluorophosphonates (which produce miosis by destroying it), though they have not actually experimented with them. As they agree with Ridley (Trans. Ophthal. Soc. U.K., Vol LVIII, ii, p. 590, 1938) that the source of the increased ocular histamine in 'glaucoma is the tears, they have been testing the conjunctival and corneal tolerance to "antispin" $\mathrm{H}_{2} \mathrm{~N} \Longleftrightarrow-\prod_{\mathrm{N}}^{\mathrm{S}}$ an anti-histaminoid. This substance causes corneal oedema, but they are hoping for better results with neo-antergan.

which closely resembles
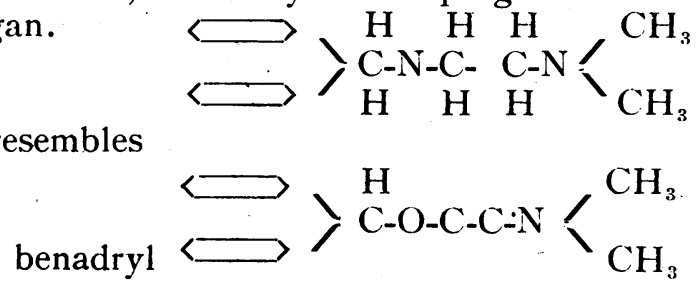

introduced here from America

for treatment of allergic conditions by mouth. They are also tracing the distribution of phosphorylated carbohydrates in different parts of the eye.

On a ward round the professor is followed by a sister with a tray of drop bottles and clean pads. He changes the pad and puts in a drop himself after examination. Squints tenotomised with a guard suture and intra-and extracapsular extractions side by side, were the only cases of note. As usual the intracapsulars were much " whiter" than the others.

I tried to obtain some idea of the organisation, standards, and methods of payment, in the University Clinics, in the incorrect 
belief that there was a State Service. As Switzerland is cantonized, and each has a different system, the Professor told me it was impossible to generalise.

\section{Schaffhausen}

I journeyed to Schaffhausen from Zurich by train (third class), and found the wooden seats quite tolerable for an hour or so. It is pleasing to find that while notices request abstention from spitting in French, German and Italian, it has not been found necessary to include one in English. Swiss railways are superbly run, and the conductors most helpful.

Grieshaber cataract knives are so well known, that I was surprised to find their factory to be a small cutler's shop.

The firm produced their first eye instruments in 1915, when the French supply failed. Even their initial efforts were a good deal superior to the French, and a challenge to the English, while certain instruments $\mathrm{cf}$. corneal trephines are superior to our own products. So good is the fit of the obturator of a Franceschetti trephine that when it is pushed home the instrument looks like a solid rod to the naked eye.

Grieshaber's supply stainless steel knives (" Rostfrei" or "Innoxydable") in preference to those of silver steel to most Swiss clinics, as they claim there is little difference in the quality of edge, and this material if sterilised by hot air eliminates the problem of rust.

Against this, I found three out of five Universities sterilise their knives chemically, and I suspect some other factor, for example the smoke (acid) free Swiss air may also play a part.

London surgeons sometimes claim that the close limits to which Grieshaber instruments are specified indicate automatic rather than manual reproduction. The firm is unwilling to say whether this is so or not, as it is a trade secret.

On the other hand, the introduction to their 1946 catalogue states that instruments are " exécutés à la main," and the appearance of the ground zone of the Grieshaber knives made in U.S.A. by a cousin of the family differs from that of the Swiss product.

Their most interesting instruments are those for keratoplasty, and I would advise those wishing to examine them to write in advance as :-

(a) certain scissors forged in Germany, and finished in Schaffhausen, are no longer available.

(b) the firm do not always "carry" their full range cf. Giradet's instruments, and only make some of them to order.

(c) some of the instruments have several uses, and discussion about them in a foreign language can be most confusing. For 
example, Franceschetti's " niblick" (Fig. 18b) can be used for both keratoplasty and dacryocystorhinostomy, and Elschnig's round-ended knife (Fig. 18a) for removing the remains of Descemet's membrane was originally designed to extend cataract sections, and is still so employed.

\section{Zurich}

An excellent account of Professor Amsler's clinic has been given in the Brit. Jl. of Ophthal., Vol. XXXI, p. 223, 1947. This is the largest clinic in Switzerland, and as will be observed from Roper Hall's account, some most interesting research work has been and is still being carried out there.

\section{Berne}

The clinic is a big one ( 70 beds), though Professor Goldmann's private work goes to a large nursing home, the other side of the river.

Professor Goldmann, who comes from Komotau in the Czech Sudetenland, was trained as a physiologist, and as in the case of Professor Brückner this perceptibly influences the trend of his papers.

Take, for example, "The Aqueous Veins," which he discovered shortly after, and quite independently of Ascher. He considers that pathologists failed to find these; as they are just like ordinary veins post-mortem.

Estimation of the total refraction (Gesamtbrechtkraft) of the eye and its comparison radiologically with its axial length, or the Stiles-Crawford effect-the apparent variation in intensity to an observer of a narrow beam of light according to the point at which it traverses the pupil. His experiments indicate that the latter is due to special properties of the retina rather than absorption by the transparent media.

For me the main interest of his work lay in his ingenuity in diagnostic instrument design, and the conclusions this has enabled him to draw on clinical subjects. He was kind enough to demonstrate the use of some of these devices, all of which are obtainable from Haag-Streit, Werkstätten für Präzísionsmechanik, Liebefeld-Bern.

Localisation of intra-ocular foreign bodies and retinal tears.-The mechanical basis of these three methods is a small metal ring whose under surface bears four obliquely directed hooks (Fig. 1). When this type of ring is applied by a twist of an applicator to a scleral or corneal surface, it adheres firmly without causing permanent damage, and can be removed when required by a twist the other way. 


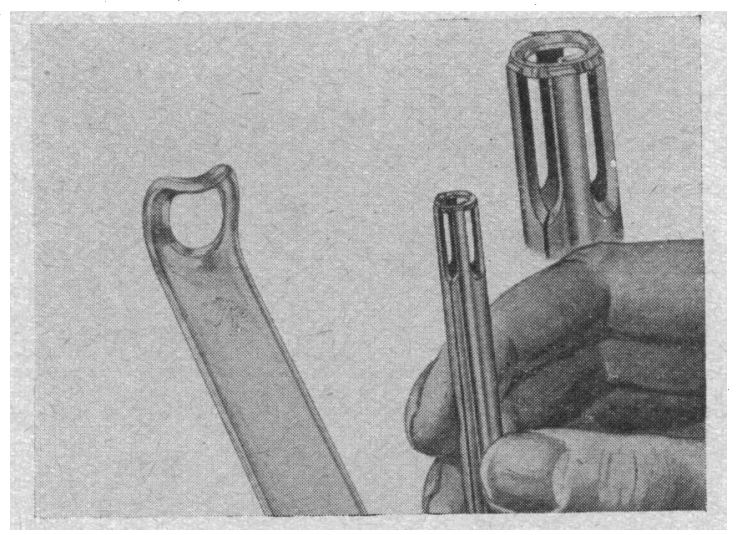

FIG. 1.

Goldmann's localising ring with applicator and plastic lid retractor.

Initial localisation.-The ring for initial localisation of intraocular foreign bodies, is about $9 \mathrm{~mm}$. in diameter. Prior to application to the cornea its hooks are dipped in Indian ink.

The marks so produced serve as "points de repère" when the ring has been removed after the X-ray.

During radiography the lids must be held back by transparent and radiotranslucent plastic retractors, or they sweep the ring off.

Non-magnetic foreign bodies.-The majority of such bodies are embedded in, or close to the scleral wall, and a modification of the above technique has proved so satisfactory that 24 out of the last 25 such bodies have been successfully withdrawn by insertion of forceps through a scleral incision at the site so indicated.

The conjunctiva is reflected over the site indicated by initial localisation, and a $3 \mathrm{~mm}$. hooked ring of the same type " screwed" on to the sclera at this point.

X-ray snapshots are taken with the patient on the operating table, the central X-ray beam being perpendicular to the plane of the ring.

The pictures are recorded on dental film cut down to an oblong of $1.5 \times 4 \mathrm{~mm}$., the open edge being sealed with strapping, and the tiny cassette so produced inserted in the finger of a rubber glove. The latter being sterilised can be held close against the sclera in the plane of the ring.

The ring is moved as the films indicate, until it overlies the foreign body.

Very rapid development is necessary in view of the multiple exposures, and is achieved by use of the following lutions :- 


$$
\begin{aligned}
A \quad 500 & \text { c.c. water } \\
50 & \text { gr. pyrocatechol } \\
50 & \text { gr. sodium sulphite }\left(\mathrm{Na}_{2} \mathrm{SO}_{3} \mathrm{Sicc}\right) \\
B \quad 500 & \text { c.c. water } \\
30 & \text { gr. sodium hydroxide } \\
50 & \text { gr. potass. bromide }
\end{aligned}
$$

Equal volumes of $\mathrm{A}$ and $\mathrm{B}$ are mixed a short time before use, as the mixture is unstable.

Development is complete in 20-35 seconds at $18^{\circ} \mathrm{C}$. The film can be examined after partial fixation, which takes another two minutes in a rapid fixative. Such films fade, and cannot be preserved for record. 'This is not important, however, as two exposures are usually enough to position the ring.

So far as I am aware, the method has not been used in this country, though a less rapid method of development taking seven minutes and using hydroquinone instead of pyrocatechol has been employed by our orthopaedic surgeons, to localise the guides for Smith-Petersen pins in the femoral neck.

The Lochfinder.-The "Hole-finder" is a tiny " $\mathrm{P}$ bulb" whose metal case bears a similar ring of hooks. This is moved about the sclera under (unlighted) ophthalmoscopic direction, until its glow coincides with a retinal tear.

Objective determination of visual acuity.-The visual acuity of children, illiterates, and malingerers, can be determined by measuring the maximum distance at which a moving test object provokes optico-kinetic nystagmus in the fixing eye.

A brightly illuminated white-painted strip is suspended from a spring, and oscillated in the vertical plane by a solenoid (Fig. 2). The strip is covered by fine black checks of a specific size, like a chessboard, and bears at its centre a strip of similar but larger check.

As the strip is seen through a slot which precludes a view of its edges, the normal eye has at 3 metres the impression of an immobile gray strip.

As soon as the patient is near enough to resolve the band of bolder check at the centre of the strip, his eye can be seen to follow it up and down.

Rieken based a night vision test on the same principle for the Wehrmacht, the patient being seated in the dark at a fixed distance from a revolving black drum painted with white strips.

The illumination of the drum was increased under photometric control until the conjunctival vessels near the outer fornix could be seen moving to and fro horizontally under a blue filtered ophthalmoscope light.

As misdirection of the light on to the pupil was liable to invalidate the test, Goldmann designed a contact lens with a clear centre 

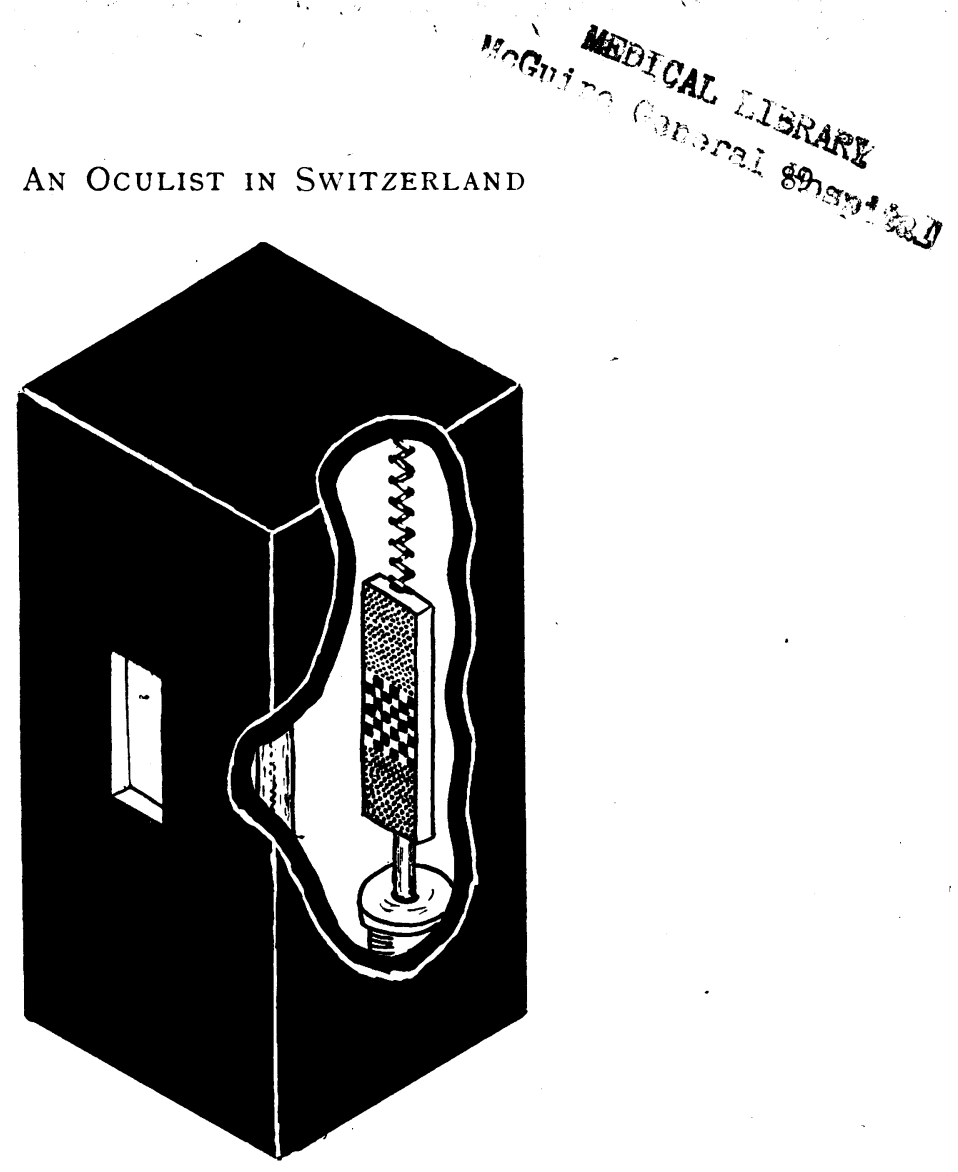

FIG. 2.

Objective determination of visual acuity (Goldmann). This is very diagrammatic, the length of chequered strip and the spring necessitating an instrument several feet high.

and eight spots of luminous paint on the blackened rim. These spots can be seen moving in the dark as soon as optico-kinetic nystagmus occurs in the wearer's eye (Fig. 3).
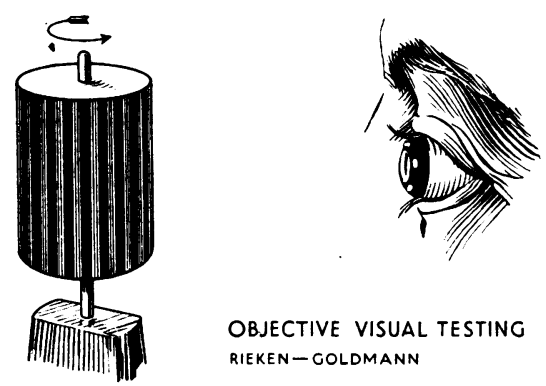

FIG. 3.

Night vision test. 
The auto-recording spherical perimeter.-As H. M. Traquair, . the leading British authority on this subject, has never ceased to point out, clinical perimetry is the most subjective form of examination in our speciality, the results are overlaid by the personal equation of examiner and examined, and it is the perimetrist not the perimeter that does the perimetry.

Goldmann, while admitting the force of this argument, holds that ultimately perimetry may become a science rather than an

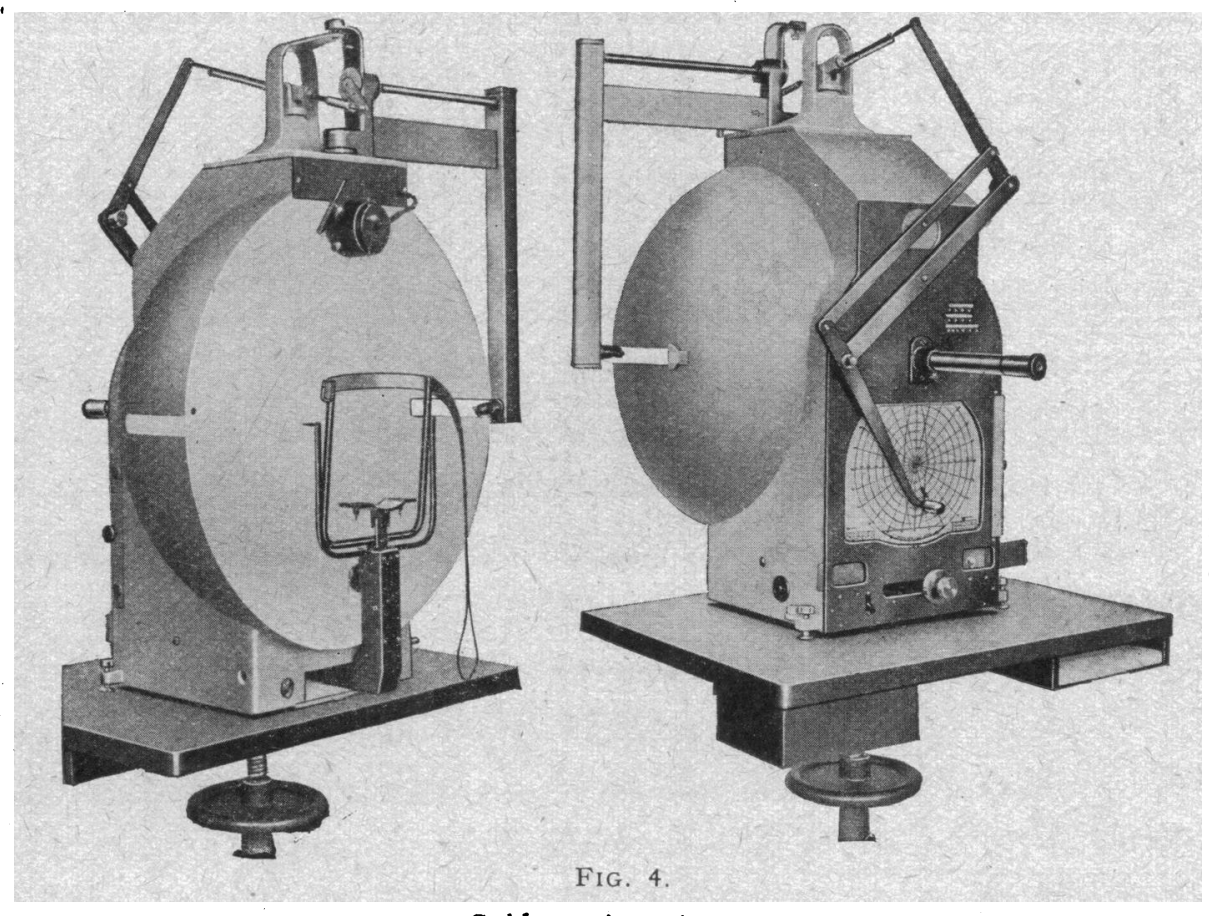

Goldmann's perimeter.

art, and that meanwhile it is possible to achieve a more standardised relative perimetry than is possible with existing instruments.

The perimeter designed to this end (Fig. 4) is the result of ten years of experiment and collaboration between Goldmann and Hans Papritz, the chief designer of Haag-Streit. I am much obliged to the latter firm for the loan of the blocks illustrating the device.

The test object is a spot of light (whose size can be varied by stops and the intensity can be controlled by filters) which is projected against a white hemispherical background whose luminosity is photometrically controlled. 
As the area, luminosity, and sharpness of the edge detérmine the stimulus, the oval shape of the spot (Goldmann claims) is unimportant, but the speed of movement ( $5^{\circ}$ per sec.) contrast. adaptation, and background illumination (about 40 f.c.) are carefully standardised.

Fixation can be continuously controlled by the surgeon through a telescope, while the ingenious pantograph permits him to advance the test object at right angles to the margin of a scotoma, under fingertip control, and while watching the chart.

The telescopic opening is so small that it only prevents scotometric mapping of the field for $1^{\circ}$ around fixation.

The isopters have been worked for objects of $0.25,1,4$, and 16 square millimetres, employing different, specific filters, on thirty men between the 20th and 30 th years, and another group between the 60 th and 70 th years.

It has been found that if the test object is enlarged four times, it will give the same peripheral isopters if its contrast with the background is reduced by 0.31 . It has also been found advisable to correct refractive errors in testing the central isopters.

It was perhaps presumptuous on my part even to attempt to criticise so ingenious and beautiful a piece of machinery, but when I examined the pantograph at the clinic the highest joint between a cone and conical hollow looked rather fragile.

I later paid a visit to the Haag-Streit factory, which is like a private house in the country, at Liebefeld-Bern, about four miles away by bus. There the manager showed me I was quite wrong in thinking this joint could easily be put out of order. He took hold of it, and shook it vigorously enough to rock the whole instrument sideways without altering the adjustment in any way.

Two other minor criticisms are also possible. First, there is a small area on the horizontal meridian in each temporal field, in which recording is impossible. This corresponds with the nicks in each side of the hemisphere, and is not of importance.

Secondly, although the reflecting surface remains unaltered in the clear Swiss air, I suspect that the filthy atmosphere of industrial England would immediately alter its reflectivity.

Against this, Professor Goldmann tells me that the surface is washable, and that the isopters depend far more on changes in contrast, which can be standardised by the built-in photometer, than on changes in the overall brightness which is dependent on the age of the bulb and the reflectivity of the background.

All Swiss clinics give the place of honour to this perimeter, and have relegated that of Maggiore to second place.

Professor Goldmann also tells me that he has compared the instrument on the same cases with Pfluger's perimeter and the Bjerrum screen, and has found it superior to both of them. 
The physiological value of the instrument is undoubted, and "a priori" one would expect it to be superior for clinical work to the perimeters employed here.

On the other hand, it costs $\mathscr{f} 180$, which as the Americans say " is not hay," and before purchase one would like to be assured by comparative tests on a series of cases that it will in practice indicate field changes of clinical importance earlier than, or has other advantages in diagnosis or prognosis over our.own perimeters.

I might add that I have submitted all my notes and reprints to Mr. H. M. Traquair, of Edinburgh, who also holds this opinion.

Binocular micro-gonioscopy.-Both these techniques are based on the Haag-Streit (1937) slit-lamp on whose design Goldmann

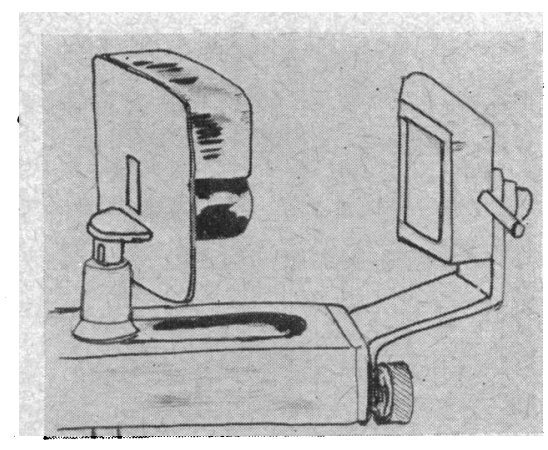

FIG. 5.

Goldmann's deviation prism fitted to Hamblin slit-lamp.

had considerable influence. I doubt if there exists a better lamp for clinical work:

As an excellent translation of Goldmann's description of the lamp and the two contact lenses is given in B.J.P.O. 1938: $13: 77$, I will confine myself to features of practical importance.

The essential attachment for both techniques is a deviation prism which swings on an arm in front of the illuminating lens, and diverts the beam by internal reflection $13^{\circ}$ right or left as required. This reduces the beam-microscope angle to $5^{\circ}$. This prism alone (on the Haag-Streit lamp) permits examination of the posterior vitreous without a contact lens. Fig. 5 shows an attachment to fix the prism to a Hamblin slit-lamp. I have insuffcient data to comment on the effectiveness of this combination as yet.

The eye is anaesthetised by a warm 0.4 per cent. diocaine 
(C.I.B.A.). This occupies a drop bottle in a thermostatically controlled heater, together with an undine containing normal saline, to fill the bowl of the contact lens. A practical British device of this type a "solution heater for two bottles" is made by Kelvin Lenses Ltd., Imperial Works, Allum Street, Manchester. Goldmann prefers diocaine as it has an almost instantaneous action.

When I tried to obtain it, C.I.B.A. informed me that " they withdrew diocaine many years ago, and advised nupercaine $1 / 100$ as a substitute."

Nupercaine is stated to be as strong as 3 per cent. cocaine, but to act more quickly (30 secs.), and must be kept in alkali free glass. Unfortunately the $1 / 1000$ solution recommended for ophthalmic use is only obtainable in England in ampoules which makes it too expensive for occasional instillation.

C.I.B.A. have kindly put up some nupercaine in drop bottles which I have employed for about nine months. The action resembles that of holocaine in " white eyes " though there is less initial irritation; corneal anaesthesia for tonometry and contact lens work is attained in one to one-and-a-half minutes and there is even less corneal disturbance.

Outside Berne, the Swiss have an expression, "Wie Ein Berner " meaning a " slow worker," so it is interesting to record that insertion and control of the contact lens, arrangement of the head on the chin rest, and focusing the lamp, requires a most un-Bernese degree of activity. The lens concavity is deep, and I find skilful handling is needed to prevent loss of saline.

The Haag-Streit lamp is a great help here, as the controls for

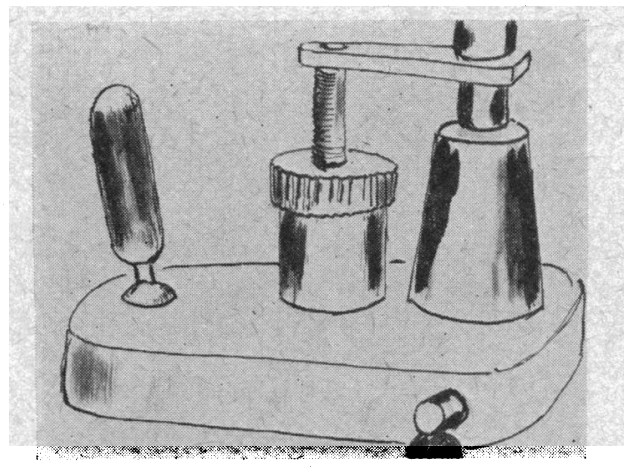

FIG. 6.

Controls of Haag-Streit slit-lamp (diagrammatic). The lever controls antero-posterior and lateral and the milled wheel the vertical movement of both lamp and microscope. (Note ball-bearing support of transyerse element). 
height, lateral and antero-posterior movements, are all in the compass of one hand (see Fig. 6), leaving the other free to tilt or rotate the contact lens as necessary, though it will often remain in situ without pressure.

I found later at the Haag-Streit factory that this lamp control is achieved by feather-light castings, and ball-bearing support of a transverse chassis element.

When you attempt these adjustments with the separated controls of an English lamp, you feel, like the Highlander who sat on an ant heap, that a third hand would be of great help.

As Busacca has indicated, the method has advantages over other methods of gonioscopy, which render it particularly suitable for clinical work. The patient is seated, an instrument in common

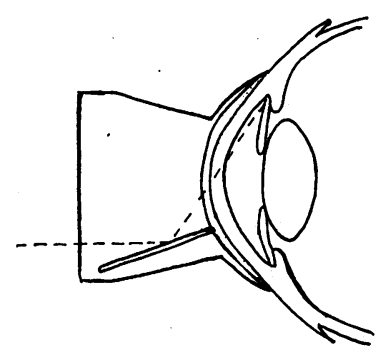

FIG. 7.

Goldmann gonioscopy lens. Dotted line represents path of incident and reflected light.

use provides $\mathrm{x} 20$ binocular vision, and a narrow beam to estimate relief. By rotating the contact lens which contains a little mirror (Fig. . 7) which both radiates the illumination in and reflects the image outwards, the whole angle is visible without moving the patient.

Incidentally, Busacca claims that the narrow beam shows the line of Schwalbe is not a prominence though to my untutored eye it appeared to be so in the cases I was shown.

The chief use of gonioscopy at Berne is to decide which glaucoma operation is indicated, and in which cases the post-operative result will be reasonably permanent.

For the narrow angles' which accompany the shallow anterior chamber of congestive glaucoma, Goldmann advises iridectomy. A poor result is foreshadowed gonioscopically by visible remains of iris root or " nipping" of the lens edge in the incision.

Dieter's iridectomy (Fig. 8) overcomes both these difficulties, though if upward dislocation of the lens still occurs (as in malignant glaucoma) an intracapsular extraction is indicated. 


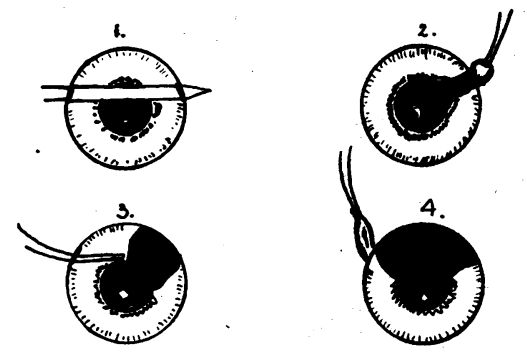

FIG. 8.

Dieter's Iridectomy

While accepting that Dieter's method has special advantages, I have found personally that it is not too easy to perform. Unless the knife is entered rather high on the limbus, the iris is elastic, and the anterior chamber fairly deep, it is difficult to get a good grip and make the second iridectomy truly basal.

For the wide angles found in the deep anterior chambers of glaucoma simplex, cyclodialysis by a slight modification of Blaskovic's method is advised.

A radial incision of $3 \mathrm{~mm}$. long starts $5 \mathrm{~mm}$. from the limbus and the spatula inserted at right angles to the incision before being swept around.

The aim is a separation of $\frac{1}{4}$ of the circumference and a good result is signalised by a permanent slit-like fistula occupying this proportion of the angle of the anterior chamber.

At this point one might conclude that the chamber depth was as good an operative indication as gonioscopy.

There is, however, a difficulty. Since 1938 certain cases of glaucoma simplex with deep anterior chambers have occurred with narrow angles.

Cyclodialysis in these cases was followed by acute glaucoma some days later.

In these cases, the cyclodialysis must be preceded by basal iridectomy in the same quadrant three weeks earlier.

It is clear both from our conversation and his "Kammerwinkel Studien beim Primarglaukom" (Ophthalmologica, p. 102, 1941), that Goldmann finds that the angle is narrow in acute and chronic congestive glaucoma.

During periods of high tension the angle may be closed over $\frac{3}{4}$ of the circumference and during periods of normal tension, though open, it invariably remains narrow.

On the other hand, his observations differ from those of the American School, as he finds no sure and specific gonioscopic abnormality in most cases of glaucoma simplex.. 


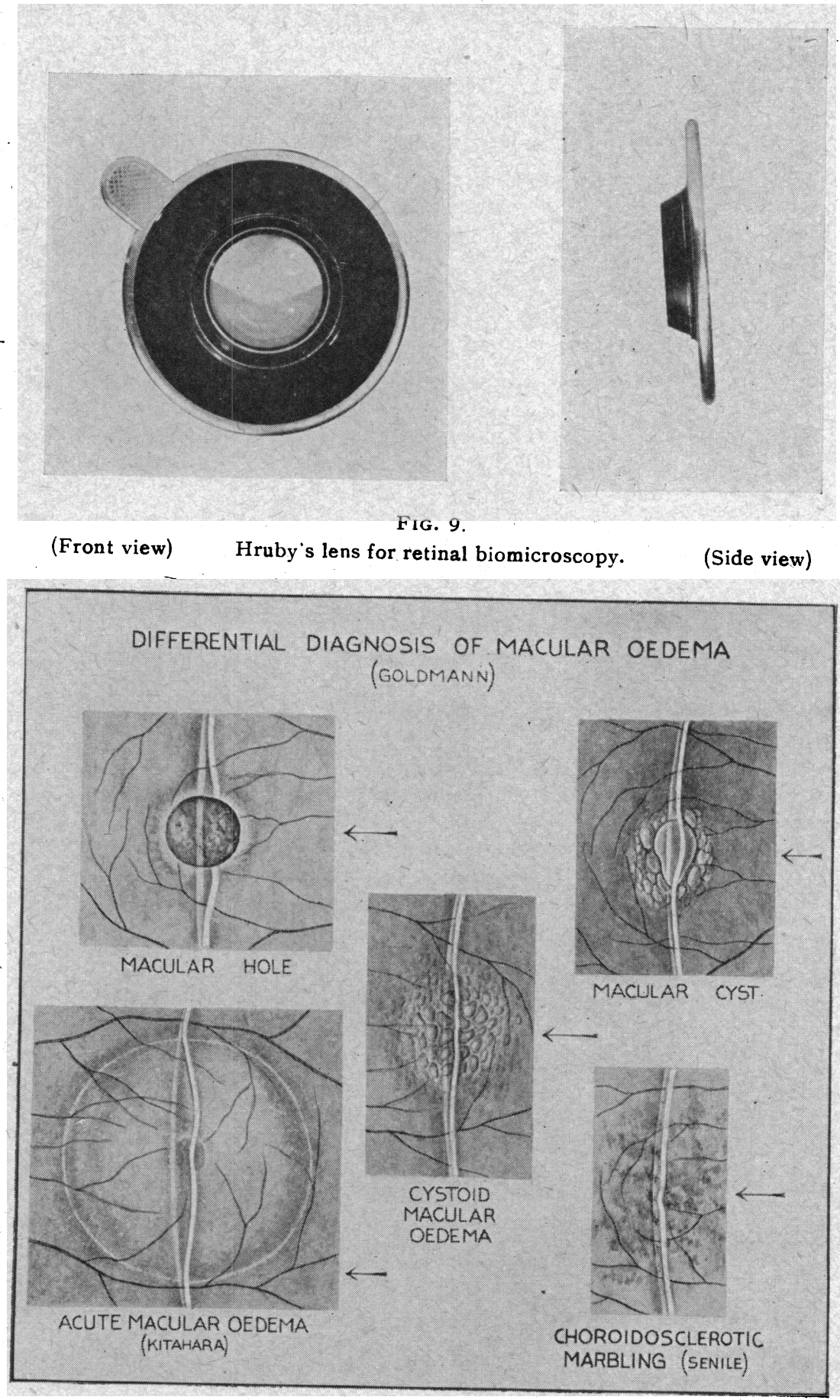

FIG. 10.

Biomicroscopy of the macula. (Drawing by Prof. Goldmann's assistant Iseli). 
Retinal biomicroscopy. - The small flat-surfaced plastic contact lens (employed in conjunction with the deviation prism) resembles that of Koeppe, but has two lateral nicks which make it easier to handle. Sallman told me in 1936 that Zeiss were attempting to produce a lighter Koeppe lens with a plane face of $15 \mathrm{~mm}$. diameter instead of the original $10 \mathrm{~mm}$. Goldmann's lens appears to realise this ideal, as it has a plane face of $14 \mathrm{~mm}$., only weighs 0.8 gramme, and remains in situ without being held. While not so simple as Hruby's method (Fig. 9) (a variant of that of Lemoine and Valois.1923, vide Lausanne) which does not require a contact lens, the optical results are superior when compared on the same case. It is difficult to get the Hruby lens really close to the eye in a trial frame.

Goldmann has developed a diagnostic technique for macular oedema, and the various possible appearances are shown in Fig. 10.

In a series of forty-two such cases, ten were due to senile choroidal' sclerosis, and were improved by twelve retrobulbar injections of 0.4 c.c. of 0.1 per cent. atropine sulphate at three-day intervals.

Although the degree of improvement is unspecified, Goldmann regards this as a "useful " measure.

In 21 cases of the same series, the case was hypertensive, thrombotic or cyclitic, and treatment was ineffective. No attempt was made to treat macular " holes " unless a detachment occurred.

To save the visual field in two such cases, after a paralysing injection of novocaine into the muscle funnel, the patient was seated in front of the slit-lamp wearing the contact lens. A fine, needle-thin electrode insulated everywhere except at the tip was introduced through a scleral incision, and passed across the vitreous through the hole itself, and into the choroid, which was thus successfully diathermised under direct vision.

Other interesting techniques were mentioned, but not demonstrated in the course of conversation. For example, diathermy of small folds blocking the lacrymal canaliculi, and the introduction of rubber tubing into the tear duct itself at the end of a wire for chronic lacrymal obstruction (Bangerter's method). (Ophthalmologica, p. 107, 1944.)

The wire is first passed like a probe from above, grasped below the inferior turbinate, and drawn out of the anterior naris by forceps.

\section{Lausanne}

This clinic is situated on a hillside with a beautiful view over Lac Léman. There are only 42 beds, but it looks larger than this, as it is joined to a blind people's home. 
Though small, this school has been made famous by the work of Gonin on detachment, and a bronze plaque is erected to his memory in the Lecture Theatre. Gonin, Streiff told me, was the typical genius, dreamy in everyday things, and wrapped up in his work.

Professor Streiff, the present incumbent, comes of an ophthalmic family, his father being a pupil of Haab, later practised as an oculist in Geneva from 1905 to 1943 . Streiff himself is a pupil of Franceschetti, and has all the wide surgical outlook of his teacher. $\mathrm{He}$ is particularly interested in lid plastics and keratoplasty. Our conversation was in French.

Keratoplasty.-He claims about 37 per cent. successes. $\mathrm{He}$ quotes Hata's ghastly case where glioma spread from donor to recipient (Acta Soc. Ophthal. Jap., Vol. XLIII, p. 1763) for preferring a cadaveric donor.

While removing the remains of Descemet's membrane with fine curved " manicure" scissors, he protects the lens with a tiny silver " niblick." This instrument (invented by Arruga for protecting the lacrymal sac during dacrocysto-rhinostomy) was adapted by Franceschetti both for lens protection, and for separating synechiae during keratoplasty (Fig. 18b).

The 5 or $6 \mathrm{~mm}$. grafts employed are always centred slightly to the inner side of the pupil. Their size obviates the necessity for pre-operative localisation of the pupil by transillumination.

Incidentally, Maurice Girardet, an oculist in Lausanne, unconnected with the clinic, has also invented several ingenious keratoplastic instruments. These include a ring for fixing the unexcised cadaveric eye while obtaining the graft (this avoids excision of the eye), deeply recurved scissors on a de Wecker mounting for removing Descemet remains, and a small " shovel " for transporting the graft itself. I am able to show the last, which he was kind enough to give me, and which. I have found most useful in two cases since (Fig. 18c).

Girardet stresses that unfortunately the prognosis is best when the opacity in the recipient cornea is limited, and that grafts rarely remain clear when the corneal opacity is total. He has illustrated this point (Jl. Suisse de Méd., Vol. XXII, p. 723, 1943) by beautiful colour photographs.

Black light.-Streiff employs "Black light" (ultra-violet) to localise dislocated lenses before, and capsular remains after, cataract extractions. I have been able to obtain the special bulb used (Typ. 57202/70 13 HPW Plhora $120 \mathrm{~W}$. Philips), but have been unable to use it as "the screw lampholders are in short supply."

$X$-ray localisation.-Dufour, Streiff's assistant, has invented a 
transparent protractor which can be applied to X-ray films taken of intra-ocular foreign bodies with a Goldmann's corneal ring (see Berne). This protractor (a) allows for the 10 per cent. distortion due to the spread of the rays, and $(b)$ if the refraction is known or the corneal diameter estimated by keratometry for variations in size from the standard eye with refractive error.

"Chenilles Processionales."-I was unaware till shown photographs, that the caterpillars whose hairs cause such trouble in children's eyes, are processional, i.e., form a long line one behind the other on a branch of the pityocampa pine. The French call them "Processionaires des Pins."

Retinal biomicroscopy.-Hruby's method (Klin. Monatsbl. $f$. Augenheilk, Vol. CVIII, p. 195, 1942) is employed to investigate " holes" in the disc and associated macular changes. This is a -55 O.D. (Busch) lens in a trial frame (Fig. 9), and with a diverted slit-lamp beam (Goldmann's prism) can be used for slit-lamp examination of the retina, without a contact lens. Streiff regards these changes as congenital, and was surprised to hear that a hole has been observed to follow a haemorrhage on the disc in England. Hruby's lenses are unobtainable in Switzerland, and this illusstrated is a copy made to my measurements by Rayner \& Co.

"Jake" toxaemia.- "Jake" (o-tri-cresyl phosphate poisoning) has been observed to cause papillomacular atrophy in a Lausanne French polisher, a point of interest in considering the effect of metabolic poisons on central vision.

On the other hand, it should be noted that Burley (Jl. Amer. Med. Assoc., Vol. XCVIII, p. 298, 1932), describes temporal disc pallor and anaesthesia as signs differentiating disseminated sclerosis from this toxaemia when caused by ingestion of 2 per cent. of this poison in Jamaica ginger (Jake) extract.

A large group of such cases was recorded elsewhere in Switzerland when 200 soldiers on a route march developed paraplegia or peripheral neuritis from food accidentally cooked in machine gun anti-rust lubricant. That so many men ate the mixture is an extraordinary tribute either to the culinary qualities of Swiss machine grease, or to Swiss Army discipline.

Tonoscopy or Ophthalmodynamometry.-Streiff is very interested in tonoscopy, and in fact has produced a book about it, "Der Retinale Blutdruck im gesunden und kranken Organismus" (Wien, 1946). Some of the component pictures of Fig. 10 are reproduced by permission from this, and some from the GirouxGuilbert Routit catalogue. This technique of estimating the retinal blood pressure may be used clinically by a few Britishers, but if so I have never heard one mention it, much less stress its value. 
The instrument usually employed by Streiff and others abroad, is the "Ophtalmo-Dynamomètre du Docteur Bailliart, à Bouton de serrage," No. 685 bis. Guilbert Routit et Cie (Fig. 11). This is a spring-loaded piston, with a rounded end, which is steadily pressed against the unanaesthetised conjunctiva overlying the insertion of the external rectus of a seated patient, until the arteries on the disc are seen by the ophthalmoscope to pulsate. Conjunctival cocainisation is only employed in the sensitive, and stress is laid on the site and steadiness of the pressure, an aim at the centre of the globe, and the tendency of the novice to get too high readings.

The button is then pressed to lock the instrument, and the pressure in grammes read on the scale by the light of the ophthalmoscope. This figure represents the diastolic pressure, and can be converted to $\mathrm{mm}$. $\mathrm{Hg}$ by nomogram. The value is about 45 per cent. of the brachial diastolic when seated, i.e., with a normal intra-ocular and normal blood pressure 28 grams $=35 \mathrm{~mm} . \mathbf{H g}$.

If the pressure is kept up till pulsation ceases, i.e. till the arter $y$

\section{OPHTHALMODYNAMOMETRY}

A

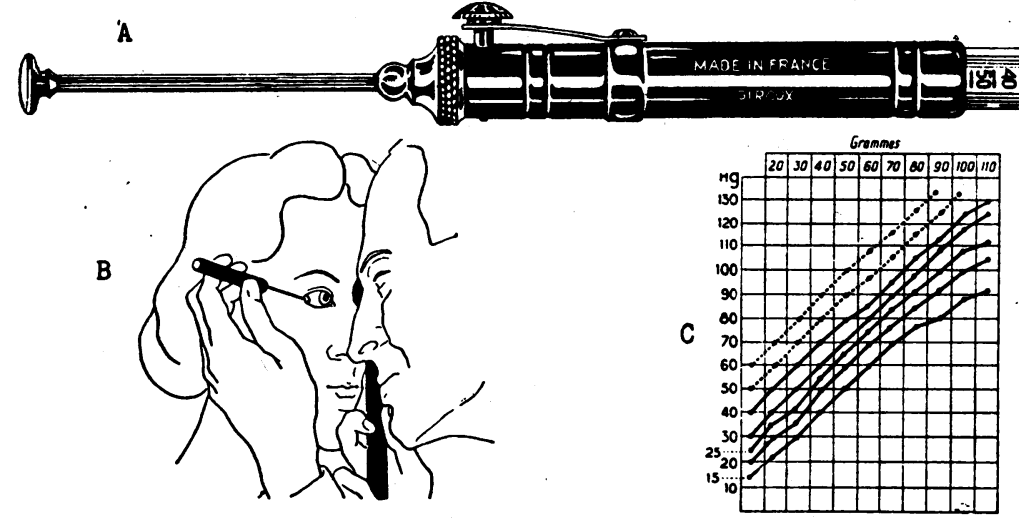

A. The Instrument. Makers: of Paris, showlng locking button and scale reading.

B. Mode of use according to Balllart, reproduced by permission of Professor Strelff, from "Der Retinale Blutdruck".

C. Magitot-Baillart Momogram. The tonometric tension is first measured by tonometer. The point of intersection of the oblique line starting from the tonometric figure and the vertical line which gives the dynamometer reading in grammes, gives the blood pressure in millimetres of mercury.

FIG. 11. 
collapses, the scale reading is regarded as representing the retinal systolic pressure. Franceschetti regards this figure as less important than the diastolic, and Dubois-Poulsen does not take it in arteriosclerotics for fear of causing permanent damage.

Although certain German authorities hold that variability of the observational norm invalidates the method, Streiff claims that :-

(1) variations of $\pm 10 \mathrm{gm}$. from the norm indicate abnormalities of intracranial blood pressure after a head injury, and may explain unduly persistent post-concussive symptoms.

(2) posterior fossa tumourrs do, and anterior fossa tumours do not raise the retinal pressure relative to the systemic.

(3) that the prognosis of hypertensive retinopathy is worse if the retinal pressure is relatively higher than the systemic.

(4) that the visual and cerebral symptoms of the " carotid sinus syndrome " intermittent visual fog, vertigo, blackout, and syncope, occur because the retinal diastolic (hence by inference, cerebral) blood pressure falls disproportionately, by 40 per cent. when the brachial falls 10 per cent.

The Carotid Sinus Syndrome.-Tschermak discovered that light massage over the carotid sinus (clinically the point of maximum carotid pulsation) produced as a rule either bradycardia, or a fall of 10 per cent. in the systemic blood pressure or both.

Some individuals are rendered hypersensitive by local arteriosclerosis, cervical tumours, digitalis, or certain neurasthenic states.

These people may develop the symptoms described above, on extending the neck in a barber's or dentist's chair, or even on blowing hard at a fire.

One such patient was horribly burnt by falling on a fire he was blowing. It was found he could produce a syncopal attack by blowing hard against the back of his hand.

Curiously enough, Streiff has found that a hypersensitive sinus often occurs on the same side as retinal thrombosis, embolism or macular oedema, and believes they may be somehow related.

Thrombosis so caused might have analogies with the " Stagnation Thrombosis" (which B. A. Klein associates with a sudden drop in blood volume after head injury, operations, or early hypertension).

I have described this technique at greater length than some might feel justified, as I feel there must be many of the same generation in this country who like myself know nothing about it.

It is difficult also to overlook either its wide acceptance abroad, or that a continental jury in 1945 awarded Bailliart the quinquennial "Prix de Gonin " for his work on the subject. 


\section{Geneva}

Professor Franceschetti is already known to many Englishmen by his visits to the U.K. Congress.

A great deal of research has been carried out in this clinic, but its main interest to Englishmen will be the superlative surgery. The existence of other less well known clinics in the city explains the relatively small size ( 35 beds) which will shortly be increased by building to sixty, with a generous allowance of room for research laboratories.

Genetics.-In one laboratory I was shown the pedigree of the Glaser family, which has now been collected for thirty-five years, and covers four metres of paper.

Ludwig Glaser died in 1550 A.D. bequeathing severally to his descendants retinitis pigmentosa, retinitis punctata albescens, nerve deafness, and Friedreich's ataxia. Some inherited one, some more of these.conditions, and Franceschetti believes a single defec- . tive gene is responsible for these varied defects.

Ocular Myology.-This is the only Swiss orthoptic department I saw which was fully equipped (with British instruments), and staffed by a wholetime orthoptist. There is such a department in Berne but I did not see it.

It is Franceschetti's interest in paralytic squint, however, which makes this clinic the centre of Swiss ocular myology, and prompts other clinics to refer difficult cases for diagnosis or treatment.

It seems to me that the vitality of the different national literatures on the treatment of ophthalmoplegia varies directly as the speed and efficiency of the test used to measure vertical deviation in the cardinal positions.

Duane's cover and parallax tests have obviously provided many American writers with a basis since the nineteen hundreds.

As the red and blue diplopia goggles, and Barlite, depend on the patient's powers of description, which are not always quick or accurate, and as the synoptophore only covers a limited zone of action, it was not until the 1930's that the extended use of the Hess co-ordimeter stimulated the British approach.

Franceschetti does not use Duane's test at all, and while not rejecting Hess's method entirely, has an approach based on four other devices of his own.

(1) Franceschetti's Cyclophoromètre.-The patient faces a tangent scale (known in Switzerland as the Croix de Maddox) at five metres, holding the cyclophorometer in front of one eye. In essentials this is a rotatable Maddox rod in a handle containing a spirit level (Fig. 12).

A trial frame is inadequate to hold the rod, as while the eyes fix the spotlight the head has to be strongly rotated to different 
AN OCULIST IN SwITZERLAND

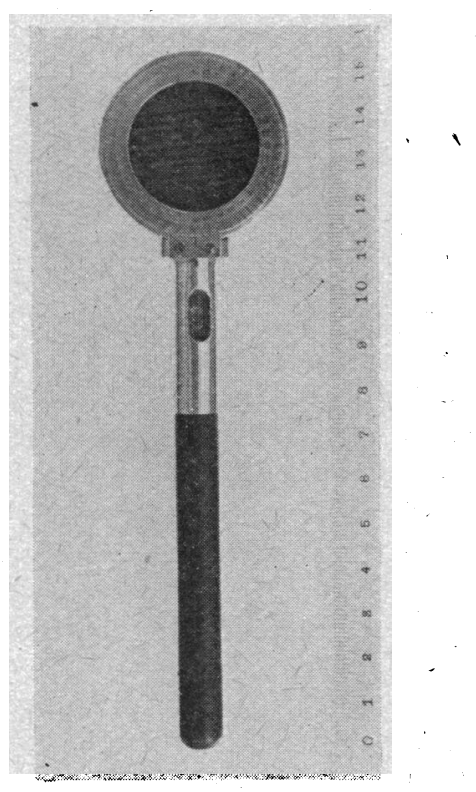

FIG. 12.

The cyclophoromètre of Franceschetti.

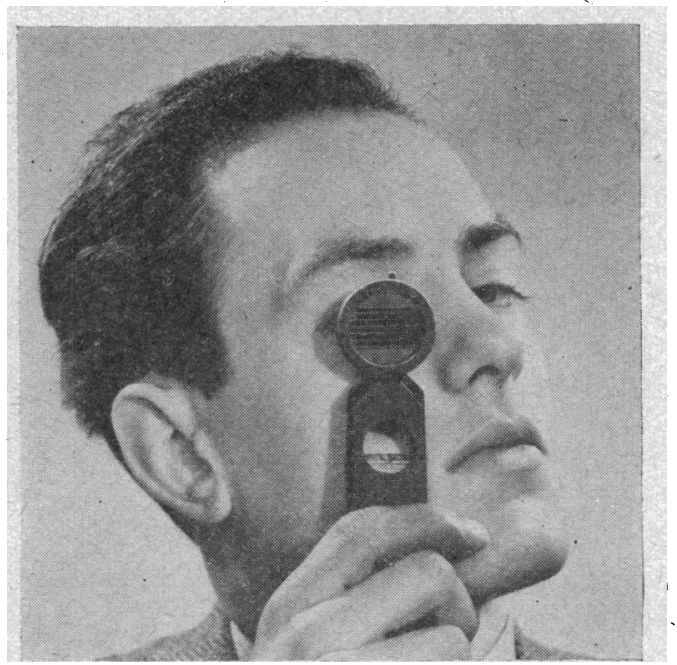

FIG. 13.

Testing of horizontal element in field of action of right inferior rectus and left superior oblique with "home-made" version of cyclophoromètre of Franceschetti. 
angles (as suggested by Landolt), and tilted backwards or forwards.

In this way not only does the patient's statement of the relation of the red line to the scale figutes establish the vertical and horizontal error in the cardinal positions, but by rotating the "rod" till it appears parallel (to him) with the horizontal arm of the scale he can indicate the varying cyclophoria at these angles.

A patient is shown holding a Leeds-made device of this type (Fig. 13) with the head angled to explore the action field of the right inferior rectus and left superior oblique.

I have found that even without the graduated protractor of the original device, the cyclophoria is much more obvious than the vertical error to a patient with a paralysed superior oblique.

$I$ also find that one is apt to forget which quadrant is being tested, a difficulty that would be overcome, of course, by systematic use.

Franceschetti regards the following signs as of diagnostic importance :-

(a) the higher eye, the tilt of the false image, variation in diplopia with vertical movement, and " applied " lateral head tilt.

(b) vertical deviation with lateral movement, and uniocular limitation of movement are regarded as less important, while :-

(c) " compensatory" head tilt and horizontal deviation in vertical diplopia are considered positively misleading. He underlines this last point in his schèma.

(2) Franceschetti's " schèma."--Most mnemonics flounder in an attempt to reconcile that the maximal vertical (diagnostic) action of a muscle is exercised in the opposite direction to its horizontal component.

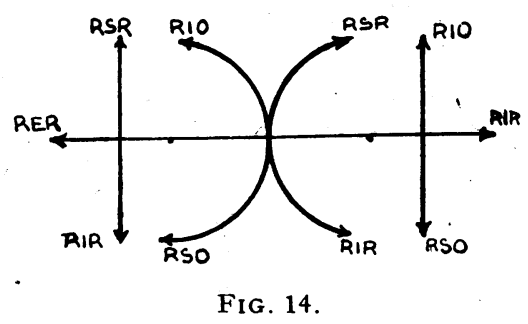

Franceschetti's schèma. "A mnemomic for the static and dynamic actions of the muscles of the right eye."

Franceschetti's schèma (Fig. 14) gets round this neatly by combining the "static". scheme of Marquez (which shows the action of the individual muscles from the primary position) with the " dynamic" scheme of Hess, which depicts the maximal vertical action in adduction or abduction. 
The combined diagram thus summarises the change in action with $30^{\circ}$ lateral traverse from the primary position.

At these angles (although cycloduction may still be of importance), van der Hoeve has shown graphically that the horizontal component is negligible or actually reversed.

(3) The double Maddox rod test.-Even the Hess screen may fail to distinguish between paralysis of the superior oblique on one side and the superior rectus on the other, when secondary contracture of the antagonist has confused the issue.

A red Maddox rod is placed in one trial frame cell, and a white one in the other. Unless they are spring clipped, as in the "Oculus" trial frame, a piece of plasticine may be necessary to hold them both firmly. The head is then tilted to either shoulder, while the patient fixes a spotlight. If the head is tilted toward the shoulder on the same side as the affected eye, the red and white lines separate vertically, and vice versa.

This replaces the Hoffman-Bielschowsky apparatus which in any case few surgeons are likely to possess, and by establishing the side of the lesion at once clarifies the diagnosis.

(4) The Franceschetti "Tableau."-The signs of diagnostic importance (A) resulting from the tests described, are applied to the table shown (Fig. 15) to identify the weak muscle.

During my trip I found this table in use in clinics as far apart as Lausanne, Marseilles, and Paris.

\begin{tabular}{|c|c|c|c|c|c|c|c|}
\hline $\begin{array}{l}\text { Vertical } \\
\text { Deviation }\end{array}$ & $\begin{array}{l}\text { The Red line } \\
\text { and Trans- } \\
\text { verse of } \\
\text { Tangent Scale } \\
\text { converge :- }\end{array}$ & $\begin{array}{c}\text { Vertical } \\
\text { Error } \\
\text { Increased by } \\
\text { Including } \\
\text { Head to :- }\end{array}$ & $\begin{array}{l}\text { Paralysed } \\
\text { Muscle }\end{array}$ & 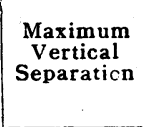 & $\begin{array}{c}\text { Maximum } \\
\text { Conver-- } \\
\text { gence of } \\
\text { Images }\end{array}$ & $\begin{array}{c}\text { Con- } \\
\text { tracted } \\
\text { Muscle }\end{array}$ & $\begin{array}{l}\text { Maximum } \\
\text { Vertical } \\
\text { Deviation }\end{array}$ \\
\hline \multirow{4}{*}{$\begin{array}{l}\text { RIGHT } \\
\text { EYE } \\
\text { HIGHER }\end{array}$} & \multirow{2}{*}{$\begin{array}{l}\text { To Right } \\
\text { (internal } \\
\text { rotators) }\end{array}$} & to $R$. & R.S.O. & L.\& & R.\& down & R.I.O. & L. \& up \\
\hline & & $\begin{array}{c}\text { to } \mathrm{L} . \\
\text { (often neg.) }\end{array}$ & L.S.R. & L. \& up & R. \& up & L.I.R. & L. \& down \\
\hline & \multirow{2}{*}{$\begin{array}{l}\text { To Left } \\
\text { (external } \\
\text { rotators) }\end{array}$} & to $\mathrm{R}$. & L.I.O. & & L. \& up & L.S.O. & R. \& $\mathrm{d}$ \\
\hline & & $\begin{array}{c}\text { to } \mathrm{L} . \\
\text { (often neg.) }\end{array}$ & R.I.R. & R. \& down & L. \& down & R.S R. & R. \& up \\
\hline \multirow{4}{*}{$\begin{array}{c}\text { RIGHT } \\
\text { EYE } \\
\text { LOWER : }\end{array}$} & \multirow{2}{*}{$\begin{array}{l}\text { To Right } \\
\text { (external } \\
\text { rotators) }\end{array}$} & to $\mathrm{L}$. & R.I.O. & L. \& up & R. \& up & R.S.O. & L. \& down \\
\hline & & $\begin{array}{c}\text { to } \mathrm{R} \text {. } \\
\text { (often neg.) }\end{array}$ & L.I.R. & L. \& down & R.\& down & L.S.R. & L. \& up \\
\hline & \multirow{2}{*}{$\begin{array}{l}\text { To Left } \\
\text { (internal } \\
\text { rotators) }\end{array}$} & to $\mathrm{L}$. & L.S.O. & R.\& down & L. \& down & L.I.O. & R. \& up \\
\hline & & $\begin{array}{c}\text { to } R . \\
\text { (often neg.) }\end{array}$ & R.S.R. & R. \& up & L. \& up & R.I.R. & R.\& down \\
\hline
\end{tabular}

Fig. 15. Franceschetti's "Tableau." 
Cases when diagnosed are treated by prisms or surgery, as we do here. Cases of superior oblique paralysis have been operated upon successfully.

Recurrent aphthous iritis.-This is a recurrent hypopyon uveitis in young people, associated with oral aphthae or generalised erythema multiforme exudativum.

At the time of my visit this condition was scarcely mentioned in the English literature though it had been called Ophthalmitis Lenta by Gilbert and Recidivierende Hypopyon Iritis in Germany. A good deal has appeared in the English medical papers since.

Known in Turkey as Behçet's (pronounced Bayshett's) disease, Behçet had actually sent a case to Franceschetti for a second opinion at this time, though in absence of aphthae it looked like any other iritis. The eight cases seen by Franceschetti were characterised by oral aphthae, recurrent hypopyon, complete resistance to all treatment, and ultimate blindness, sometimes from micro-cysts at the macula.

The possible relationship to bovine foot and mouth disease (though there are no nail lesions), and recurrent equine ophthalmia, is of great interest in view of past discoveries regarding brucellotic uveitis, and Vail's recent work on the toxoplasma. I asked if "sarcoidosis known there as the "Maladie de BesnierBoeck" (pronounced Bayneeay-Book) might also have an animal vector, but was told " no."

Corneal Grafts.-Of the 110 corneal grafts done by Franceschetti in the last few years, 32 per cent. obtained a visual increase of 10 per cent., 14 per cent. were improved to $6 / 60,34$ per cent. retained the visual status quo, and 20 per cent. actually had worse vision post-operatively.

Franceschetti while recognising the existence of this last group (sometimes overlooked by other writers on this subject) regards it as no deterrent, as he is prepared to regraft such cases. With a normal anterior chamber the graft and bed are the same size, with a flattened cornea the graft is cut $0.1 \mathrm{~mm}$. larger.

Large $(5$ or $6 \mathrm{~mm}$.) trephines are employed, with an adjustable piston to prevent undue penetration (Fig. 16).

The piston fits so well that it requires a specially drilled vent to prevent air compression, and the edge (see section on Schaffhausen) is better than anything available here. The cost at present is rather high (about $£ 12$ a pair).

Franceschetti prefers trephines to knives, and believes the Americans have been driven to a knife technique by inferior instruments.

He regards the prognosis as good in disciform and interstitial keratitis, the apical scar of keratoconus, and heredo-familial dystrophy. 


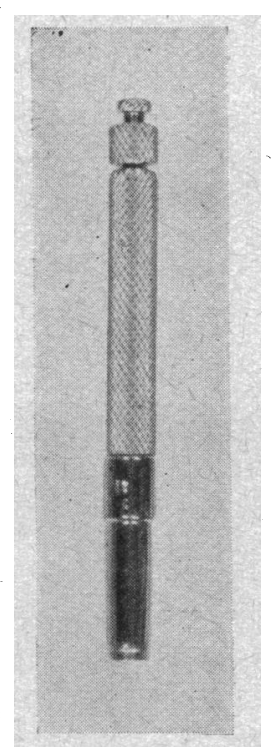

FIG. 16.

Franceschetti's trephine

I have been unable to trace a case history where the latter condition was grafted, and the graft invaded by the dystrophic process, but there seems to be a general belief in England and America that this always occurs.

Franceschetti disagrees, and produced as proof a farmer with Groenouw's type “ B " dystrophy (see- Fig. 20') grafted in 1935. This man had 6/9 and J.1 (uncorrected) in the better eye, and although the peripheral cornea was rough and the eyes irritable, there was no biomicroscopic evidence of invasion of the disc in either.

After I had examined him, the patient (obviously most grateful for the operative result) insisted on signing and giving me a little cyclostyled copy of his history. He had come to Geneva in 1935 to obtain a blind pension certificate, after four other hospitals had told him nothing more could be done.

Franceschetti has grafted thirteen similar eyes, and has employed the material to supplement Bückler's classification.

This successful approach stimulated me to base the table (Fig. 20) on facts from his papers, to show the constitution, location, depth and progress of the different types. Franceschetti was kind enough to correct it.

Recent senile cadaveric corneae are preferred, as the donor source, as he holds the graft to be merely a " scaffold," and the more inert the better. 
The graft is stored up to seventy-two hours at $45^{\circ} \mathrm{C}$. in holofusine (a sterile, pyrogen-free, isotonic Ringer type solution of essential blood salts, made by Haussman et Cie of St. Gall, but unobtainable here).

The solution is kept in a petri-dish and the graft is lowered into it on a small porcelain "strainer" with a central handle like an inverted mushroom. Fig. 17 which Professor Franceschetti kindly gave me.

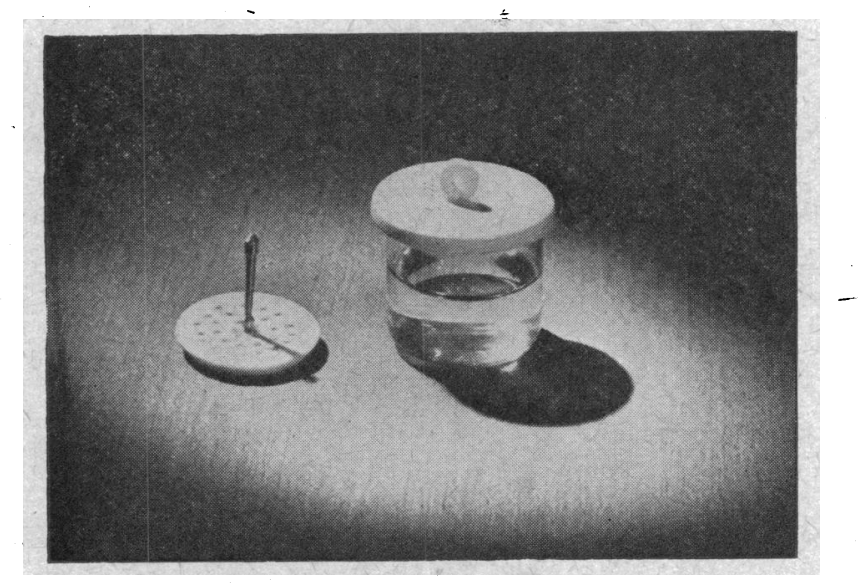

FiG. 17.

Corneal graft "strainer" Franceschetti.

As nothing of this shape is available here, and it is difficult to attach a handle to a porcelain filter disc, I got Thackrays to make a similar device out of chromium plated stainless steel.

Unless one has a " corneal bank" it is difficult to do a corneal graft just when one wants, so that Jean Nordmann "Chef de Clinique " at Strasbourg and myself had to wait until evening, when it was hoped a donor might become available.

The operation at 9 p.m. was a re-graft on a young man with interstitial keratitis, and $6 / 12$ in the other eye.

A willingness to graft a bad eye when the other has good vision is, I feel, the acid test of a surgeon's belief in his technique.

Franceschetti, when operating, uses sterile linen gloves, retrobulbar anaesthesia; Arruga's speculum, scialytic lighting, and broad-toothed fixation forceps. A drop of pilocarpine is inserted half-an-hour before operation.

Four marks are made on the limbus at 12,3,6 and 9 o'clock, with methyl violet, and double armed sutures are inserted at these points. 
Franceschetti's trephine (Fig. 16) cuts a very clean disc, and a thin remaining strand of Descemet's membrane was easily divided by Elschnig's " Hornhautmesser" (Fig. 18a) while the opaque

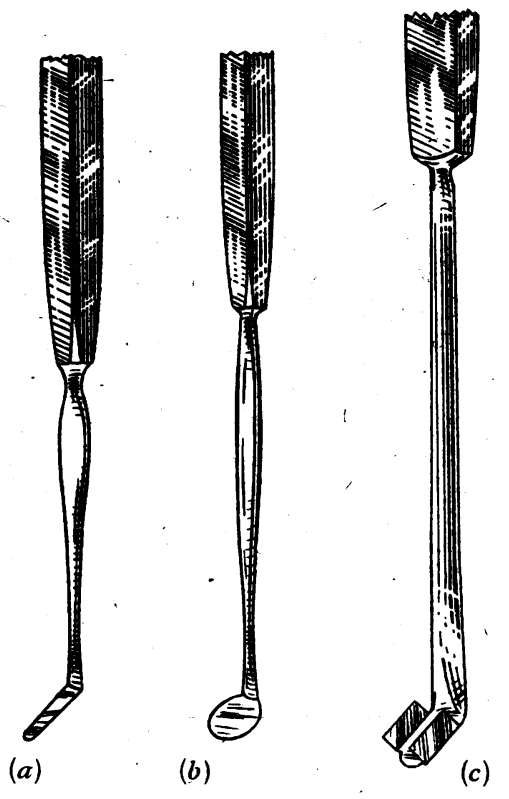

FIG. 18.

(a) Elschnig's " hornhautmesser."

(b) Franceschetti's " niblick."

(c) The "pelle" of Girardet.

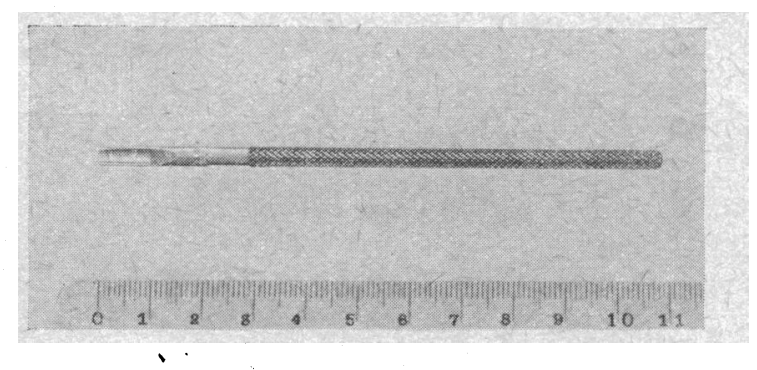

FIG. 19.

Franceschetti's gouge for removing Descemet remains.

disc was held in forceps, and the lens was protected by the little " niblick" -shaped silver spatula held by an assistant (Fig. 18b).

This instrument is then swept round the anterior chamber to detach any synechiae. 


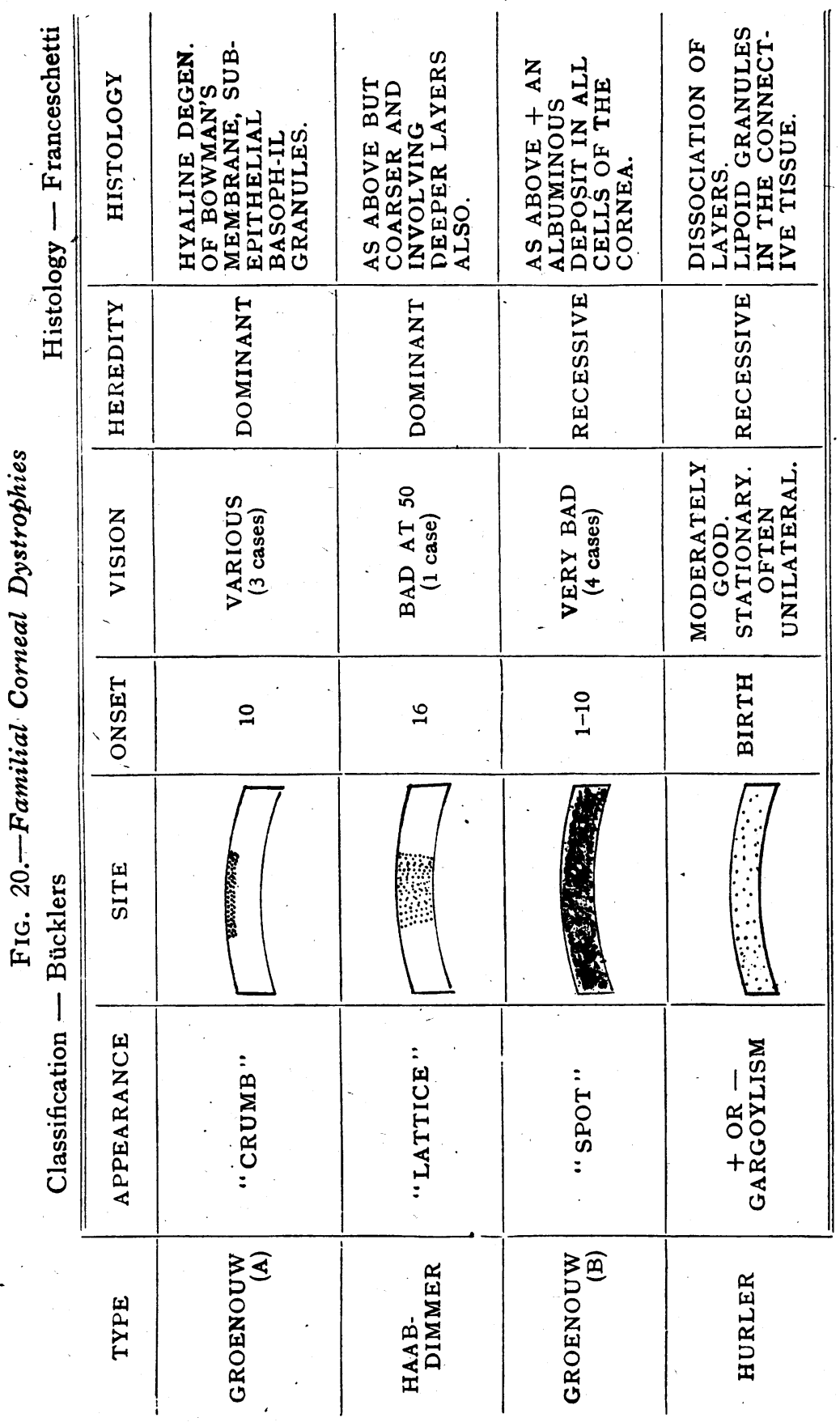


The Hornhautmesser (Augenarztliche Operationslehre 1922: 525 : Fig. 447) is an angled knife, with a blunt point and two lateral edges. The English reproduction (Fig. 18a) is by Down Bros.

Had any ungraspable Descemet tags remained attached to the edge of the trephine bed, they would have been divided against the " niblick" by a tiny gouge-shaped instrument (Franceschetti's) equivalent to about $\frac{1}{8}$ of the diameter of a $5 \mathrm{~mm}$. corneal trephine (Fig. 19).

Strands of Descemet's membrane rarely remain attached to the graft itself, but if they do highly curved scissors are to be preferred to the instruments above, as the pressure or traction necessary for their use might damage it. Though the cutting action of instruments for removing these strands varies greatly it should be noted that the most successful have a common feature-a curved cutting edge concentric with or of smaller arc than the trephine hole.

The graft was. lifted out of the holofusine on its little "strainer," pushed on to the back of a metal lid spatula repositor, and from there to its bed by an iris repositor. The sutures were tied, argyrol inserted and the eyes double-padded. Time about 25 minutes.

Among the instruments in reserve were Arruga's forceps, which can be employed to put sutures directly through the graft edge at two points if there is a vitreous loss.

It is difficult to convey in a bald account of the technique the smoothness and absolute confidence of the whole procedure.

\section{RETINAL ARTERY OCCLUSION \\ A Report Illustrating the Pathogenesis of the Fundal Appearances and the effect of Acetyl-choline*}

BY

\section{C. Michaelson \\ GLASGOW}

THE following case is described because it illustrates :-

(1). The rôle of spasm in arterial occlusion and the effect of acetyl-choline ;

(2). A relationship between arterial spasm and anatomical changes in the vessel wall;

(3). The nature of the retinal opacity with the influence of the capillary distribution in determining its extent.

* Received for publication, August 9, 1947. 